\title{
Peer feedback as a strategy to foster feedback literacy in first-year allied health students
}

\section{Nicholas Tripodi[1], Brett Vaughan[2], Rebecca Wospil[1]}

Corresponding author: Mr Nicholas Tripodi nicholas.tripodi@vu.edu.au

Institution: 1. Victoria University, 2. University of Melbourne

Categories: Assessment, Educational Strategies, Students/Trainees, Teaching and Learning, Research in Health

Professions Education

Received: 07/10/2020

Published: 10/05/2021

\begin{abstract}
Introduction

Developing a student's capacity to provide and utilise feedback are transferable skills from classroom to employment. Feedback literacy encompasses a student's ability to recognise, understand and take action on feedback. The link between feedback literacy and peer feedback remains under investigated. The aims of this project were twofold: firstly, to evaluate first-year allied health students' behaviours and attitudes towards feedback; and secondly, to assess the capability of these students to provide peer feedback.
\end{abstract}

\section{Methods}

Participants were first-year osteopathy students enrolled at Victoria University, Melbourne in 2019. Feedback learning activities were embedded throughout the year. Firstly, participants were invited to complete a Likert questionnaire to assess their behaviours and attitudes towards feedback. The survey was administered at three time points throughout the year. Secondly, the quality of peer feedback provided by the students was assessed at two time points (semester one and two) using a quantitative rubric.

\section{Results}

A significant difference was identified in student behaviours and attitudes towards feedback over time $(\mathrm{p}<0.05)$. Peer feedback rubric scores significantly improved between semester one and two $(\mathrm{p}<0.001)$.

\section{Discussion}

First-year allied health student behaviours and attitudes towards feedback can develop throughout a study year. Participating in peer-feedback tasks, and the associated learning activities appeared to improve peer feedback quality. This may be due to experience with the task, the development of feedback literacy, and/or developing an appreciation of actionable feedback from peers. These findings highlight a potential link between feedback literacy and peer assessment and has implications for university curriculum design and workplace learning. 


\section{Conclusion}

Developing peer feedback capabilities may assist in fostering feedback literacy. How students develop feedback literacy and use feedback to improve performance requires additional investigation.

Keywords: Allied health; Evaluation; Peer assisted learning; Peer Feedback; Quantitative methods

\section{Introduction}

Increasing numbers of students undertaking tertiary education-with subsequent changes in educational design, delivery and teaching load for educators-has challenged educators to provide constructive, meaningful feedback to their students. Consequently, research is exploring strategies to foster student agency in the feedback process, improve feedback literacy and evaluate the role of students as partners in the feedback process (Carless and Boud, 2018; Dawson et al., 2019; Henderson et al., 2019; Molloy, Boud and Henderson, 2019). Feedback is contextual, but in a broader sense, according to Ramaprasad (1983) is "...information about a gap between the actual level and the reference of a system parameter, which is used to alter the gap in some way" (p. 4). Within the education setting, Carless and Boud (2018) define it as "a process through which students make sense of information from various sources and use it to enhance their work or learning strategies" (p. 1315). Regardless of the definition, a large body of literature demonstrates that feedback is pivotal in improving performance and in increasing satisfaction across a range of educational settings (Poulos and Mahony, 2008; Bing-You et al., 2017).

Feedback is central to the learning process and can foster improved decision making, ultimately improving a student's ability to achieve their learning outcomes (Higgins, Hartley and Skelton, 2002; Orsmond and Merry, 2013; Scott, 2014; Henderson et al., 2019). It is argued that the traditional construct of feedback in the educational context is too teacher-centred and needs more student input to be truly reflective of how all educational stakeholders perceive feedback (Scott, 2014). A desire to move away from a teacher-centred model to a more contemporary student-centred model has been described (Nicol, Thomson and Breslin, 2014; Dawson et al., 2019; Chong, 2020). This contemporary model emphasises not only student-centeredness, but also a process-orientated approach, where students synthesise feedback information themselves, and apply it to an education or work setting (Johnson et al., 2016; Chong, 2020).

Feedback, as a tool to improve both academic and clinical performance within the health professions is widely utilised. However, the culture of feedback in these professions is underpinned by often informal and ad hoc feedback, lacking a consistent approach to its delivery and utilisation (Van De Ridder et al., 2008; Johnson et al., 2016; Kornegay et al., 2017). Effective feedback in this setting often involves an intention and purpose, observations and standards of comparison, all with the aim of promoting knowledge, skill development, student-centeredness and educator guidance (Van De Ridder et al., 2008; Johnson et al., 2016; Bing-You et al., 2017; Noble et al., 2020). It appears that health professions educators are aware of these underpinnings in their teaching practice, and report that the feedback they give to their students is adequate (Bing-You et al., 2017). However, it appears many students feel like they receive insufficient feedback (Sender Liberman et al., 2005; McIlwrick, Nair and Montgomery, 2006; Johnson et al., 2016; Noble et al., 2020). This represents a gap between the educator and student perceptions of the same pieces of unique feedback. There has been a call for improved methods to teach students how to more effectively ask for, and receive feedback, and to train students and educators in more evidence-based and consistent feedback strategies (Milan, Dyche and Fletcher, 2011; Johnson et al., 2016; Kornegay et al., 2017; Tekian et al., 2017). In short, developing higher levels of feedback literacy amongst health professions learners may assist them in achieving higher level competency-based outcomes. 
A proposed definition of feedback literacy is the ability to understand and act on information to enhance learning or work strategies (Carless and Boud, 2018). In their conceptual paper, Carless and Boud (2018) propose a framework composed of four key features of student feedback literacy: 1. Appreciating Feedback (student conceptualising the value of feedback, and centrality of their role in feedback); 2. Making Judgements (students judging the quality of their own work and that of others); 3. Managing Affect (resolving emotional responses to feedback); and 4. Taking Action (action the students take in response to the feedback they have received). Limited student feedback literacy may be a significant hurdle to uptake of feedback (Carless and Boud, 2018). Students react to and conceptualise feedback in unique ways, across all its dimensions, and this must be paramount when considering strategies that aim to improve feedback literacy. The role of feedback literacy in health professions education, and in higher education more broadly remains under investigated, specifically, the interrelationship between peer feedback and feedback literacy.

Peer feedback is a process where students provide feedback to, and receive feedback from their peers (Nicol, Thomson and Breslin, 2014). Authors postulate that its effectiveness is due to it being conveyed in a way that students comprehend it more effectively, when compared to educator feedback (Nicol, Thomson and Breslin, 2014). Furthermore, given enough exposure to peer feedback, students are more likely to seek further feedback and clarification on their results (Nicol, Thomson and Breslin, 2014). This effect appears to be enhanced by receiving feedback from multiple peers, rather than a single peer (Topping, 1998; Cho and MacArthur, 2010). Without effective feedback guidance and support, learning improvements are not likely to take place,(Sadler, 2010; Patton, 2012) suggesting there may be a 'skill' component to peer feedback. Peer feedback is now common place in health professions education, with multiple studies showing student perceived benefits (Dupras and Edson, 2011; de la Cruz, Kopec and Wimsatt, 2015; van Schaik et al., 2016). What is less clear in the literature, is the relationship between peer feedback and feedback literacy. Carless and Boud (2018) suggest peer feedback can aid in the development of student feedback literacy through promotion of student-centeredness, allowing them to make judgements and take action on feedback, therefore closely aligning to their proposed feedback literacy framework. It can be therefore be argued that effective peer feedback, will promote improved feedback literacy, which ultimately may reduce the educator workload and improve student academic success.

Considering these knowledge gaps within the field, the broad aims of this project were to provide an insight into how peer feedback impacts upon feedback literacy within a cohort of first-year allied health students. More specifically, the aims were twofold: firstly, to quantitatively evaluate these students' behaviours and attitudes towards feedback, and secondly, to assess the capability of these students to provide peer feedback, to ascertain if these capabilities develop throughout the course of a study year.

\section{Methods}

\section{Ethical Approval}

Ethical approval was obtained from the Victoria University Human Research Ethics Committee (Approval Number: HRE 17-192).

\section{Participants}

One hundred and thirty-eight ( $\mathrm{N}=138$ ) first-year osteopathy students were enrolled in Evidence and Research, Clinical Skills 1 and Clinical Skills 2 at Victoria University (Melbourne, Australia) across semesters one and two, 2019. One hundred and fourteen students $(n=114)$ completed the surveys at $T 1$, forty seven $(n=47)$ at $T 2$ and sixty seven $(n=67)$ at T3. Thirty $(n=30)$ participants completed the surveys at all three time points, representing a $22 \%$ response rate. All $138(\mathrm{~N}=138)$ student's marks for the peer feedback assessments in Clinical Skills 1 and 2 were analysed. 


\section{Institutional Setting, Course and Unit Specifics}

At the time of evaluation, all undergraduate subjects in the osteopathy course were delivered in a 'block-mode' format. This format consisted of three, three-hour workshops each week (with slight variations in contact hours between subjects, mainly determined by the unit content). Students completed each of their four-week units individually, with four units completed per semester. In Australia, osteopaths are nationally registered allied health practitioners who assess and manage musculoskeletal conditions (Osteopathy Board of Australia, 2014). In the firstyear of the course, students complete two evidence and communication units, four anatomy and physiology units, and two clinical skills units. The subjects that the evaluations took place in were 'Evidence and Research', which took place in block one, semester one, and 'Clinical Skills 1 and 2', which took place in block four of semester one and two respectively.

\section{The Peer Feedback Activity}

The practice Observed Performance in a Simulated Setting (OPSS) assessment assessed the ability of the students to give feedback to a peer, and was informed best practice on peer feedback (Carless and Boud, 2018; Tai et al., 2018; Dixon, Hawe and Hamilton, 2019). The final OPSS is the students' last, and most heavily weight assessment for the subject. They are required to demonstrate adequate musculoskeletal examination and management skills in a casebased setting to pass, therefore there is a practice OPSS midway through the unit. For the practice OPSS students were given an exemplar completed feedback assessment, as well as access to the rubric in advance of the assessment date. Each student had a 40-minute period to note their feedback, verbally explain it to their peer and submit the assessment. A copy of the written feedback was also emailed to the peer after the assessment, so they could refer to it at a later date if they wished. Both dialogic and written forms of feedback were used here to cater for different student feedback responses and to harness the positives of both these forms of feedback (Xu and Carless, 2017).

\section{Feedback Education Modules}

Feedback education modules were developed for the students to develop their feedback literacy, based on the principles of feedback literacy proposed by Carless and Boud (2018). The semester one modules focused on the 'how' and 'why' i.e. appreciating feedback and managing affect, whereas the semester two modules and activities built on this information and the onus was shifted to the student to not only initiate the feedback process, but to make judgements and take action. Figure 1 represents the scaffolding and development of the feedback modules in the context of the study year.

Figure 1: The sequential sequence of the eight, first year osteopathy subjects, and their associated feedback modules and focus. 


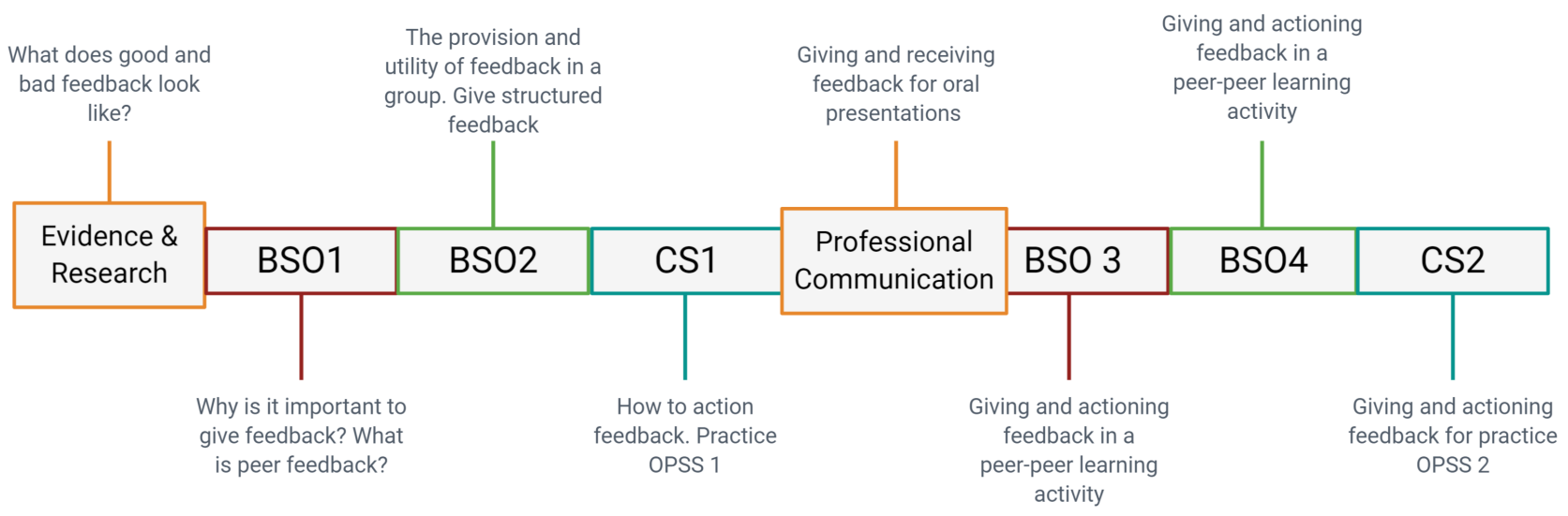

\section{Study Design and Evaluations}

A quantitative, longitudinal survey study design was used. Firstly, a questionnaire to assess student's feedback literacy and their behaviours and attitudes towards feedback was developed and administered. Completion of the questionnaire was voluntary and not a requirement of the assessments for the subjects. As there was not a suitable questionnaire developed in the literature, all items on the questionnaire were adapted from the framework by Carless and Boud (2018) (Appendix 2). The questionnaire comprised item on: 1. Appreciating feedback (items 1-3, 4, 16-18); 2. Making judgements (items 4, 11-13); 3. Managing affect (items 5, 7-10); and 4. Taking action (items 6, 15, 19-21). Response options to each item were on the Likert-type scale ranging from 5: strongly agree, to 1: strongly disagree. Cronbach's alpha was used to evaluate the internal consistency of the Likert-type scale questions $(\alpha=$ 0.864 ) showing that there was high internal consistency and reliability of the survey. The survey was administered at three time points: T1. At the beginning of semester one; T2. At the end of semester 1; and T3. At the end of semester 2. The total score for each was summated and used for analysis.

Secondly, the student's ability to provide feedback to a peer was assessed as part of their Clinical Skills 1 and 2 units. The mark contributed to $10 \%$ of their total grade for each unit. The assessment was completed in groups of three. Each student took turns in playing the role of either patient, practitioner, or examiner. While the student was playing the examiner, their task was to give the 'practitioner' feedback using the practical examination marking sheet, guided by a rubric. Two members of the teaching team marked these assessment and were additionally cross marked to ensure marking consistency. The rubric used to mark the students peer feedback ability was developed by the teaching team adapted from work by Carless and Boud (2018) and Bing-You et al. (2017) (Appendix 1). It is also worthy to note, that the rubric criteria were purposely kept broad to account for the current level of feedback literacy amongst first-year students (Carless and Boud, 2018). These two assessments took place two weeks before the student's final OPSS clinical exams in semester one and two, 2019. The scores for each student were summated and used for analysis.

\section{Data Analysis}

Survey responses and peer feedback assessment results were manually entered into Microsoft Excel (Microsoft, USA). Quantitative data were exported into, then analysed using SPSS statistical package, version 25 (IBM Corp., Armonk, NY, USA). Cronbach's alpha was used to evaluate the internal consistency of the Likert-type scale questions. Demographic data was reported in means and frequencies. Inferences into the population sample $(\mathrm{n}=30)$ was used to compare the survey results at three time points. Comparisons to the initial sample size $(n=114)$ were made using Mann-Whitney- $U$ and Pearson's chi-squared tests were made to screen for potential response bias. 
Further inferential statistics analysis, in the form of a repeat-measures ANOVA and a paired samples t-test, were used to analyse the feedback questionnaire results and the feedback rubric scores respectively

\section{Results/Analysis}

\section{Feedback questionnaire}

One hundred and fourteen $(\mathrm{n}=114)$ students completed the feedback behaviours and attitudes questionnaire at $\mathrm{T} 1$ with thirty $(n=30)$ completing the questionnaire at T1, 2 and 3 representing a $22 \%$ response rate. Descriptive statistics for the cohort are presented in Table 1. A Mann-Whitney- $U$ test displayed no significant difference between ages ( $U=1032, p=0.128)$, nor was there any significant difference between the T1 questionnaire scores of the participants who completed the survey at T1 only, and all 3 time points $(p=0.930)$ (Table 1). There were no significant differences between the T1 and T1-3 groups in terms of English as a first language $(p=0.133)$ and gender $(p=0.929)($ Table 1$)$.

\section{Table 1: Demographic data of participants for the feedback behaviours and attitudes questionnaire based on response to $\mathrm{T} 1$ only versus all three time points.}

\begin{tabular}{|c|l|l|}
\hline & $\begin{array}{l}\text { Time 1 only }(\mathbf{n}=\mathbf{1 1 4}, \\
\mathbf{8 4 \%})\end{array}$ & $\begin{array}{l}\text { All time points } \\
(\mathbf{n = 3 0 , 2 6 \%})\end{array}$ \\
\hline Age (mean, SD) & $21( \pm 4.8)$ & $23( \pm 7.8)$ \\
\hline Gender & & \\
\hline Male & $60(52.6 \%)$ & $16(53.3 \%)$ \\
\hline Female & $54(47.4 \%)$ & $14(46.7 \%)$ \\
\hline Highest level of education completed & & \\
\hline High school & $58(50.9 \%)$ & $12(40 \%)$ \\
\hline Vocational education & $4(3.5 \%)$ & $2(6.7 \%)$ \\
\hline Bachelor degree & $46(40.4 \%)$ & $15(50 \%)$ \\
\hline Graduate certificate & $3(2.6 \%)$ & $1(3.3 \%)$ \\
\hline Grad diploma & $3(2.6 \%)$ & $0(0 \%)$ \\
\hline Speak English at home & & \\
\hline Yes & $108(94.7 \%)$ & $30(100 \%)$ \\
\hline No & $6(94.7 \%)$ & $0(0 \%)$ \\
\hline
\end{tabular}

Mean feedback behaviours and attitudes survey scores were: T1 - $90.1( \pm 1.2)$; T2 - $92.8( \pm 1.3)$; and, T3 - 93.0 $( \pm 1.5)$. The scores at the three time points were found to be normally distributed. A repeated-measures ANOVA identified a significant difference in student behaviours and attitudes towards feedback over time with a small effect size $\left(\mathrm{p}<0.05\right.$, partial eta $\left.{ }^{2}=0.12\right)$. Despite this, no significant difference was found between any specific time point ( $\mathrm{p}$ $>0.05$ ) (Figure 2).

Figure 2: Feedback behaviours and attitudes survey score throughout the 3 time points. 


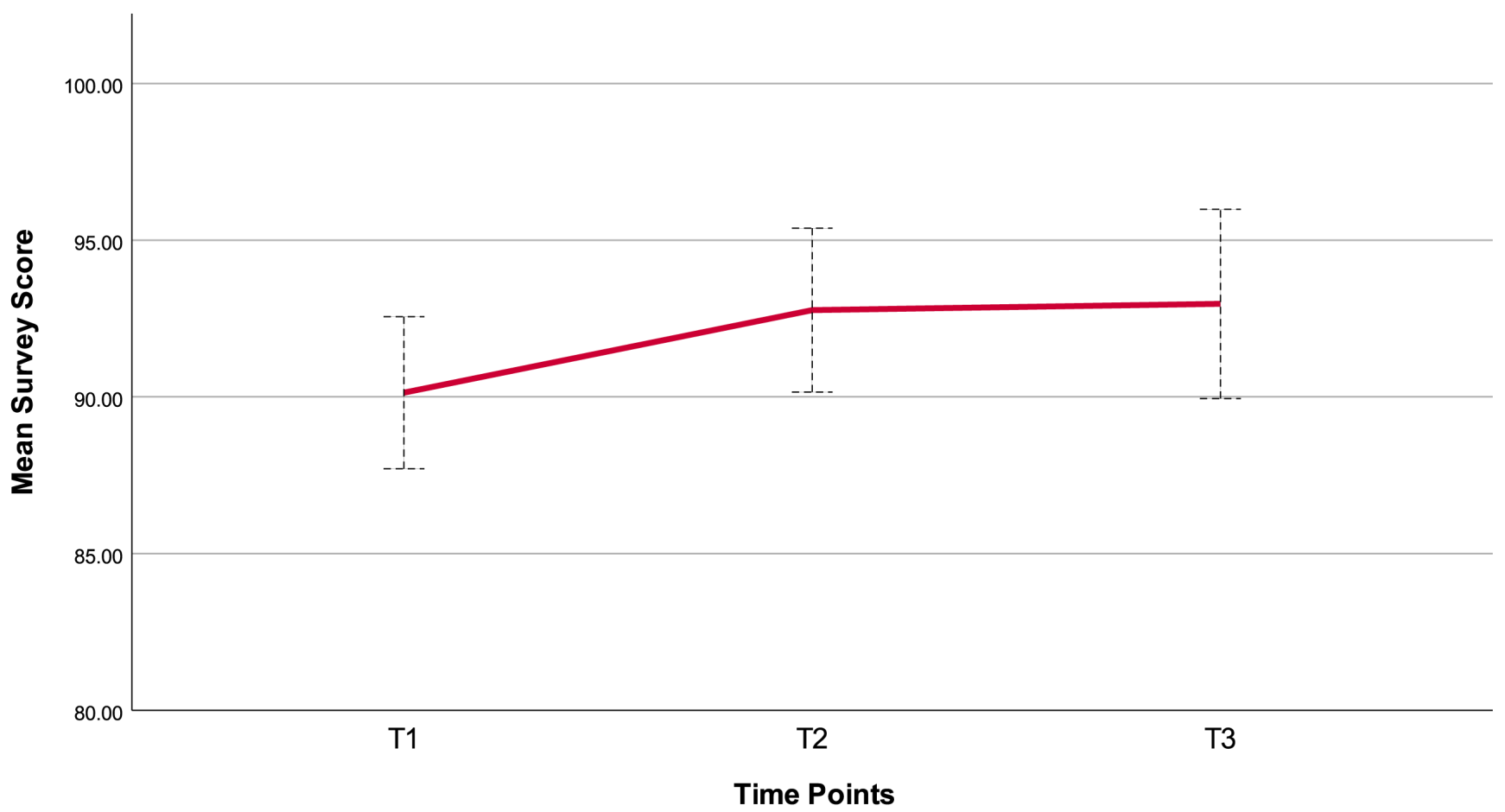

Error Bars: $95 \% \mathrm{Cl}$

Assessment of the peer feedback rubrics was completed in week 12 of semester one and two, 2019. The mean mark in semester one was $14.30( \pm 0.195)$, and $15.76( \pm 0.176)$ in semester two. A paired-samples t-test indicated this difference as being statistically significantly $(\mathrm{p}<0.001)$ (Figure 3$)$.

Figure 3: Feedback rubric mark scores at the two assessed time points throughout the semester. The semester 2 mark was significantly higher when compared to semester 1 .

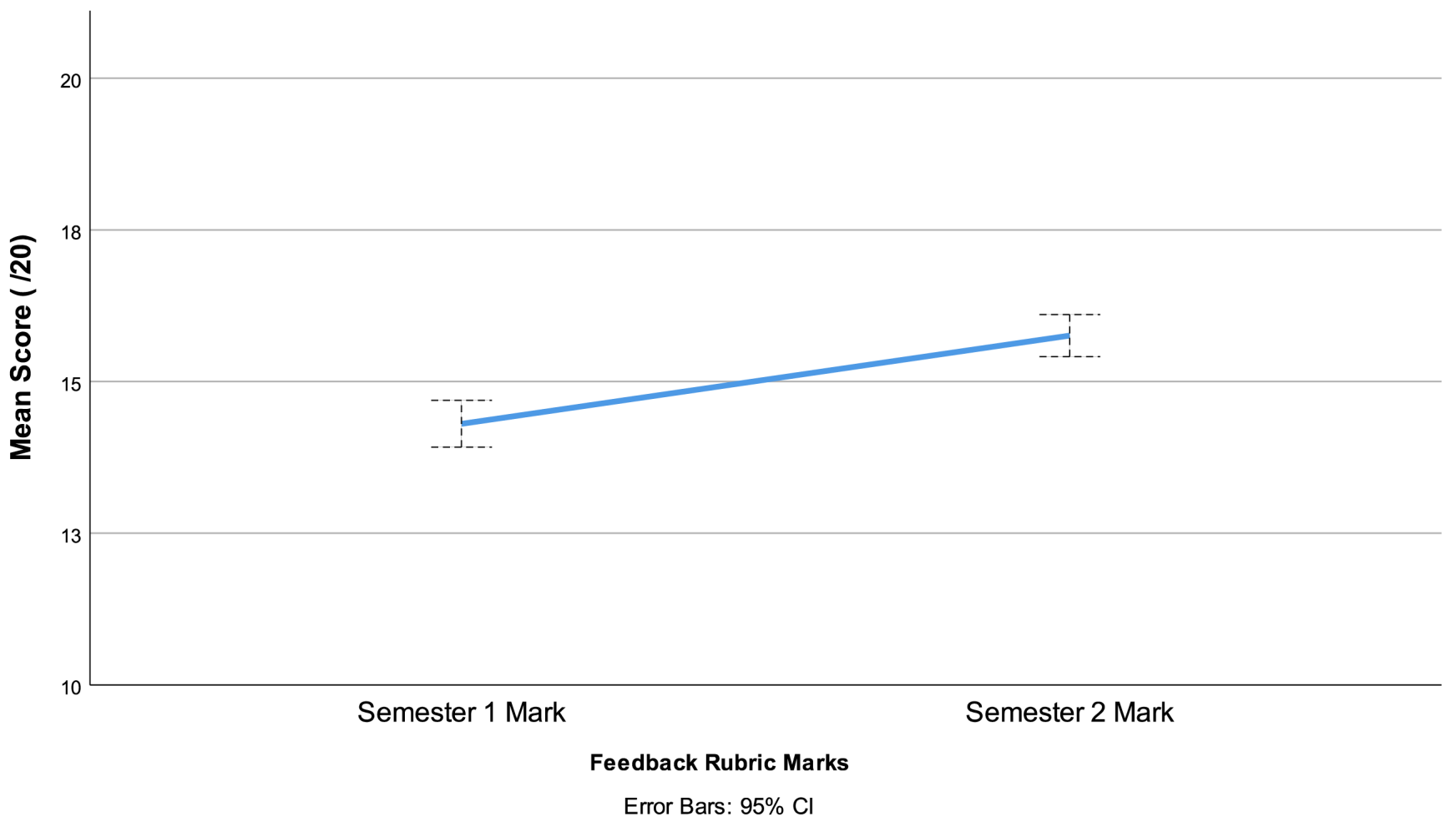




\section{Discussion}

Feedback literacy is an emerging concept in higher education (Carless and Boud, 2018; Chong, 2020; Noble et al., 2020). Peer feedback activities are theorised to foster feedback literacy by facilitating student-centred feedback and student appreciation of feedback, which allows for improved discourse and the development of students' decision making skills in relation to feedback (Carless and Boud, 2018). Our study addressed these two areas in the following ways: 1 . by quantitatively assessing student's feedback behaviours and attitudes throughout a study year and; 2 . by assessing the student's ability to provide peer feedback in a simulated setting. The overarching results of this study show that both these measures in conjunction with feedback-focussed structured learning activities and assessments, improved throughout the study year.

Peer feedback is a common pedagogical strategy in tertiary education (Hoo, Tan and Deneen, 2020). The ability to assess the work of peers can build the ability to make judgement on subsequent work, and may allow the peer assessor to better self-assess (Carless and Boud, 2018; Hoo, Tan and Deneen, 2020). The students who participated in our study were encouraged to use both the educator and student feedback they received in the semester one assessment, to inform their subsequent semester two assessment. By achieving an improved average mark in the provision of peer feedback over this time period, the learners in this cohort have demonstrated an ability to make judgement and take action on current and previous feedback, hence we can infer they have exhibited an enhanced degree of feedback literacy. Additionally, this task appears to align with a further benefit of peer feedback being affording the learners timely feedback before their graded submissions,(Wimshurst and Manning, 2013) thus having a potential positive effect on their achievement of clinical competencies.

While much research has found that student's perception of peer feedback is generally positive,(Patton, 2012) there are reports of student dissatisfaction with these tasks in the social-affective domain. Specifically, students reacted strongly to disrespectful feedback from peers, highlighting the importance of guiding students in appreciating what respectful, and constructive feedback is (Zhou, Zheng and Tai, 2019). Using the feedback literacy behaviours and attitudes survey as surrogate measure, we surmise the guidance provided to the students, in conjunction with the feedback rubric assessment, and feedback learning modules (Figure 1) facilitated an improvement in their ability to manage affect when providing and receiving feedback. Additionally, our results may provide support to the summation by Carless and Boud (2018) that peer feedback can foster feedback literacy if students are guided effectively, develop competencies with respect to feedback provision, and display positive feedback seeking behaviours. Therefore, we demonstrated a simultaneous improvement in both peer feedback provision, and feedback behaviours and attitudes, demonstrating a potential conduit between these elements and feedback literacy. More importantly, the nurturing of feedback skills and 'setting a feedback standard' at first-year level, may instil positive feedback behaviours, potentially leading to further downstream effects on learning and graduate outcomes (Carless and Boud, 2018).

The results from our feedback behaviours and attitudes questionnaire suggest that participating in feedback-centred learning and assessment activities may enhance student feedback literacy through improved learner agency. Both the feedback literacy models proposed by Carless and Boud (2018) and Chong (2020) note the importance of the student in the uptake of feedback. The modern focus of learner agency in the feedback process is critical, as it develops the ability of the student to better act upon the feedback and therefore improve their performance in subsequent tasks (Chong, 2020; Noble et al., 2020). Through the structured learning activities, modules and assessments given to the students, a strong emphasis was placed on the development of a progressive level of autonomy when it came to both the provision and utility of feedback. In turn, these curricula activities may have been a key driver of the changes in behaviours and attitudes towards feedback during the study year. 
The development of feedback literacy can be strongly influenced by the educator (Sutton, 2012; Xu and Carless, 2017; Henderson et al., 2019; Carless and Winstone, 2020). Therefore, it is not enough for the educator to only present the feedback activities, they must play an active role in fostering an environment where student feedback literacy can develop (Sutton, 2012; Johnson et al., 2016; Carless and Boud, 2018). In developing the feedbackrelated tasks for this cohort, we placed an importance on the educator's role in facilitating the co-construction student knowledge about the process and benefits of feedback, with the aim of developing the student's ability in appreciating feedback and making judgements (Carless and Boud, 2018; Tai et al., 2018; Carless and Winstone, 2020). Aligned with the work of Carless and Chan (2017) and Nicol, Thomson and Breslin (2014), we propose that of these feedback activities and assessments, the introduction of exemplars was important in facilitating this behaviour change. Exemplars provide students with a concrete example of not only the requirements of the task, but also the standard of quality to which it should be (Tai et al., 2018; Carless and Winstone, 2020). Effective exemplars should not only accurately represent the task in its entirety, they should also inspire sustained student confidence and task competence (Dixon, Hawe and Hamilton, 2019). Additionally, they allow students to discriminate between varied levels work quality and begin to develop evaluative judgement (Carless and Chan, 2017). Exemplars embedded with these features promote academic self-efficacy, a strong predictor of academic success (BartimoteAufflick et al., 2016). It is likely that the emphasis of student-centeredness and evaluative judgement, and further the gradual increase in feedback autonomy, initially facilitated by the educator may, in part, be responsible for the selfreported changes in feedback behaviours and attitudes and the improvement in the provision of feedback.

\section{Limitations and Future Research Directions}

There are a number of limitations in this study. The feedback behaviours and attitudes questionnaire was developed for the study by the research team as there was no suitable questionnaire for this project at the time of data collection. Although grounded in the feedback literacy framework described by Carless and Boud (2018) and the high level of internal consistency, the feedback survey we employed should be subject to further validation and development. Self-reported data are also susceptible to acquiescence and social desirability biases, and these cannot be discounted in our work. Secondly, the sample size for the survey represented only $22 \%$ of the cohort. Despite the differences in demographics and initial survey scores between the T1 only group and the T1-3 groups demonstrating no significant mean differences, the results may have been influenced by self-selection bias. Thirdly, given the students underwent a range of feedback-related learning activities and assessments, it is hard to discern which learning activities may have contributed to the potential development of feedback literacy. However, given that the contributors to feedback literacy are multifactorial, we posit a suite of learning activities will have the most profound effects on its development. Finally, although there was a significant difference in the peer review activity score between $\mathrm{T} 1$ and $\mathrm{T} 2$, the score change was only $1.5 / 20$, how educationally relevant this is requires further investigation.

Further research could be directed towards exploration of how students utilise the feedback provided to them through the peer feedback task. The use of a qualitative methodology may also allow for a more in-depth exploration of what feedback literacy means to the student within the context of peer assessment. There are also opportunities for longitudinal evaluation of how (or if) students' feedback literacy evolves over a course, and the relationship of feedback literacy with assessment outcomes.

\section{Conclusion}

This study sought to evaluate the feedback literacy behaviours and attitudes of a first-year allied health student cohort. Our work suggests that through feedback-specific educational activities and participation in peer assessment and feedback, behaviours and attitudes towards and competency in provision of feedback may occur. These strategies are likely easily implemented across a range of teaching contexts. Our findings suggest there may be a link 
between the development of feedback literacy and peer feedback, however additional work is required to support this assertion. How students develop feedback literacy and use feedback to improve performance over the duration of their program of study also requires additional investigation.

\section{Take Home Messages}

- Research suggests there is a disconnect between provision of feedback, and learners recognising and using this feedback.

- Students' attitudes and behaviours towards feedback can develop throughout a study year.

- Participating in peer-feedback tasks, and the associated learning activities appears to improve peer feedback quality.

- These changes and improvements may reflect enhanced feedback literacy.

- These findings are likely to be applicable to many educational settings.

\section{Notes On Contributors}

\section{Nicholas Tripodi}

Nicholas is a Teaching Focused Academic within the Osteopathic discipline in the First Year College and a PhD candidate within the Institute for Health and Sport. Nicholas is a strong advocate for improving the student experience and for promoting student-driven teaching and learning processes. Nicholas' education-related research interests includes: Feedback literacy and attitudes; student engagement and learning styles; and patient and practitioner communication and experiences. ORCID ID: https://orcid.org/0000-0001-5062-0409

\section{Brett Vaughan}

Brett Vaughan is a lecturer in clinical education in the Melbourne Medical School, University of Melbourne, Melbourne, Australia and a Professional Fellow in the School of Health \& Human Sciences, Southern Cross University, Lismore, Australia. His interests include assessment and evaluation in the clinical learning environment and faculty development. ORCID ID: https://orcid.org/0000-0002-8623-4558

\section{Rebecca Wospil}

Rebecca is a Teaching Focused Academic within the First Year College. In conjunction with her teaching role, Rebecca has worked in the healthcare industry for more than 10 years, primarily as an osteopath. Rebecca believes that balancing clinical practice with teaching enhances the learning experience for students and is focused on creating a learning environment that is student-centered and engaging. Her research interests include near-peer teaching and feedback literacy. ORCID ID: https://orcid.org/0000-0002-7239-2432

\section{Acknowledgements}

The authors would like to thank their respective institutions (The University of Melbourne and Victoria University) for their ongoing support. NT is supported by an Australian Government research training program scholarship, and would like to acknowledge their support.

Source of Figures 1 - 3: The Authors. Figure 1 created using https://biorender.com/

\section{Bibliography/References}

Bartimote-Aufflick, K., Bridgeman, A., Walker, R., Sharma, M., et al. (2016) 'The study, evaluation, and 
Tripodi N, Vaughan B, Wospil R

MedEdPublish

https://doi.org/10.15694/mep.2021.000115.1

improvement of university student self-efficacy', Studies in Higher Education, 41(11), pp.

1918-1942. https://doi.org/10.1080/03075079.2014.999319

Bing-You, R., Hayes, V., Varaklis, K., Trowbridge, R., et al. (2017) 'Feedback for learners in medical education: What is known? A scoping review', Academic Medicine, 92(9), pp. 1346-1354.

https://doi.org/10.1097/ACM.0000000000001578

Carless, D. and Boud, D. (2018) 'The development of student feedback literacy: enabling uptake of feedback', Assessment \& Evaluation in Higher Education, 43(8), pp. 1315-1325.

https://doi.org/10.1080/02602938.2018.1463354

Carless, D. and Chan, K. K. H. (2017) 'Managing dialogic use of exemplars', Assessment \& Evaluation in Higher Education, 42(6), pp. 930-941. https://doi.org/10.1080/02602938.2016.1211246

Carless, D. and Winstone, N. (2020) 'Teacher feedback literacy and its interplay with student feedback literacy', Teaching in Higher Education, pp. 1-14. https://doi.org/10.1080/13562517.2020.1782372

Cho, K. and MacArthur, C. (2010) 'Student revision with peer and expert reviewing', Learning and instruction, 20(4), pp. 328-338. https://doi.org/10.1016/j.learninstruc.2009.08.006

Chong, S. W. (2020) 'Reconsidering student feedback literacy from an ecological perspective', Assessment \& Evaluation in Higher Education, pp. 1-13. https://doi.org/10.1080/02602938.2020.1730765

Dawson, P., Henderson, M., Mahoney, P., Phillips, M., et al. (2019) 'What makes for effective feedback: Staff and student perspectives', Assessment \& Evaluation in Higher Education, 44(1), pp.

25-36. https://doi.org/10.1080/02602938.2018.1467877

de la Cruz, M. S. D., Kopec, M. T. and Wimsatt, L. A. (2015) 'Resident perceptions of giving and receiving peer-topeer feedback', Journal of Graduate Medical Education, 7(2), pp. 208-213.

https://doi.org/10.4300/JGME-D-14-00388.1

Dixon, H., Hawe, E. and Hamilton, R. (2019) 'The case for using exemplars to develop academic self-efficacy', Assessment \& Evaluation in Higher Education, pp. 1-12. https://doi.org/10.1080/02602938.2019.1666084

Dupras, D. M. and Edson, R. S. (2011) 'A survey of resident opinions on peer evaluation in a large internal medicine residency program', Journal of Graduate Medical Education, 3(2), pp. 138-143.

https://doi.org/10.4300/JGME-D-10-00099.1

Henderson, M., Phillips, M., Ryan, T., Boud, D., et al. (2019) 'Conditions that enable effective feedback', Higher Education Research \& Development, 38(7), pp. 1401-1416. https://doi.org/10.1080/07294360.2019.1657807

Higgins, R., Hartley, P. and Skelton, A. (2002) 'The conscientious consumer: Reconsidering the role of assessment feedback in student learning', Studies in Higher Education, 27(1), pp.

53-64. https://doi.org/10.1080/03075070120099368

Hoo, H.-T., Tan, K. and Deneen, C. (2020) 'Negotiating self-and peer-feedback with the use of reflective journals: an analysis of undergraduates' engagement with feedback', Assessment \& Evaluation in Higher Education, 45(3), pp. 
Tripodi N, Vaughan B, Wospil R

MedEdPublish

https://doi.org/10.15694/mep.2021.000115.1

431-446. https://doi.org/10.1080/02602938.2019.1665166

Johnson, C. E., Keating, J. L., Boud, D. J., Dalton, M., et al. (2016) 'Identifying educator behaviours for high quality verbal feedback in health professions education: literature review and expert refinement', BMC Med Educ, 16(1), p.

96. https://doi.org/10.1186/s12909-016-0613-5

Kornegay, J. G., Kraut, A., Manthey, D., Omron, R., et al. (2017) 'Feedback in medical education: a critical appraisal', AEM Education and Training, 1(2), pp. 98-109. https://doi.org/10.1002/aet2.10024

Mcllwrick, J., Nair, B. and Montgomery, G. (2006) '"How am I doing?": many problems but few solutions related to feedback delivery in undergraduate psychiatry education', Academic Psychiatry, 30(2), pp. 130-135.

https://doi.org/10.1176/appi.ap.30.2.130

Milan, F. B., Dyche, L. and Fletcher, J. (2011) '"How am I doing?" Teaching medical students to elicit feedback during their clerkships', Medical Teacher, 33(11), pp. 904-910. https://doi.org/10.3109/0142159X.2011.588732

Molloy, E., Boud, D. and Henderson, M. (2019) 'Developing a learning-centred framework for feedback literacy', Assessment \& Evaluation in Higher Education, pp. 1-14. https://doi.org/10.1080/02602938.2019.1667955

Nicol, D., Thomson, A. and Breslin, C. (2014) 'Rethinking feedback practices in higher education: a peer review perspective', Assessment \& Evaluation in Higher Education, 39(1), pp. 102-122.

https://doi.org/10.1080/02602938.2013.795518

Noble, C., Billett, S., Armit, L., Collier, L., et al. (2020) '"It's yours to take": generating learner feedback literacy in the workplace', Advances in Health Sciences Education, 25(1), pp.

55-74. https://doi.org/10.1007/s10459-019-09905-5

Orsmond, P. and Merry, S. (2013) 'The importance of self-assessment in students' use of tutors' feedback: A qualitative study of high and non-high achieving biology undergraduates', Assessment \& Evaluation in Higher Education, 38(6), pp. 737-753. https://doi.org/10.1080/02602938.2012.697868

Osteopathy Board of Australia (2014) About. Available at: https://www.osteopathyboard.gov.au/About.aspx (Accessed: 22 April 2020).

Patton, C. (2012) 'Some kind of weird, evil experiment': student perceptions of peer assessment', Assessment \& Evaluation in Higher Education, 37(6), pp. 719-731. https://doi.org/10.1080/02602938.2011.563281

Poulos, A. and Mahony, M. J. (2008) 'Effectiveness of feedback: The students' perspective', Assessment \& Evaluation in Higher Education, 33(2), pp. 143-154. https://doi.org/10.1080/02602930601127869

Ramaprasad, A. (1983) 'On the definition of feedback', Behavioral Science, 28(1), pp.

4-13. https://doi.org/10.1002/bs.3830280103

Sadler, D. R. (2010) 'Beyond feedback: Developing student capability in complex appraisal', Assessment \& Evaluation in Higher Education, 35(5), pp. 535-550. https://doi.org/10.1080/02602930903541015

Scott, S. V. (2014) 'Practising what we preach: towards a student-centred definition of feedback', Teaching in Higher 
Education, 19(1), pp. 49-57. https://doi.org/10.1080/13562517.2013.827639

Sender Liberman, A., Liberman, M., Steinert, Y., McLeod, P., et al. (2005) 'Surgery residents and attending surgeons have different perceptions of feedback', Medical Teacher, 27(5), pp. 470-472.

https://doi.org/10.1080/0142590500129183

Sutton, P. (2012) 'Conceptualizing feedback literacy: knowing, being, and acting', Innovations in Education and Teaching International, 49(1), pp. 31-40. https://doi.org/10.1080/14703297.2012.647781

Tai, J., Ajjawi, R., Boud, D., Dawson, P., et al. (2018) 'Developing evaluative judgement: enabling students to make decisions about the quality of work', Higher Education, 76(3), pp. 467-481.

https://doi.org/10.1007/s10734-017-0220-3

Tekian, A., Watling, C. J., Roberts, T. E., Steinert, Y., et al. (2017) 'Qualitative and quantitative feedback in the context of competency-based education', Med Teach, 39(12), pp. 1245-1249.

https://doi.org/10.1080/0142159X.2017.1372564

Topping, K. (1998) 'Peer assessment between students in colleges and universities', Review of Educational Research, 68(3), pp. 249-276. https://doi.org/10.3102/00346543068003249

Van De Ridder, J. M., Stokking, K. M., McGaghie, W. C. and Ten Cate, O. T. J. (2008) 'What is feedback in clinical education?', Medical Education, 42(2), pp. 189-197. https://doi.org/10.1111/j.1365-2923.2007.02973.x

van Schaik, S. M., Regehr, G., Eva, K. W., Irby, D. M., et al. (2016) 'Perceptions of peer-to-peer interprofessional feedback among students in the health professions', Academic Medicine, 91(6), pp. 807-812.

https://doi.org/10.1097/ACM.0000000000000981

Wimshurst, K. and Manning, M. (2013) 'Feed-forward assessment, exemplars and peer marking: evidence of efficacy', Assessment \& Evaluation in Higher Education, 38(4), pp. 451-465.

https://doi.org/10.1080/02602938.2011.646236

Xu, Y. and Carless, D. (2017) 'Only true friends could be cruelly honest': cognitive scaffolding and social-affective support in teacher feedback literacy', Assessment \& Evaluation in Higher Education, 42(7), pp. 1082-1094. https://doi.org/10.1080/02602938.2016.1226759

Zhou, J., Zheng, Y. and Tai, J. H.-M. (2019) 'Grudges and gratitude: the social-affective impacts of peer assessment', Assessment \& Evaluation in Higher Education, pp. 1-14. https://doi.org/10.1080/02602938.2019.1643449

\section{Appendices}

Appendix 1: Peer feedback marking rubric

\begin{tabular}{|l|l|l|l|l|l|}
\hline Criteria & $\mathbf{5}$ & $\mathbf{4}$ & $\mathbf{3}$ & $\mathbf{2}$ & $\mathbf{1}$ \\
\hline $\begin{array}{l}\text { Feedback } \\
\text { volume }\end{array}$ & $\begin{array}{l}\text { Feedback is } \\
\text { provided for all } \\
\text { 4 parts of the } \\
\text { assessment. }\end{array}$ & $\begin{array}{l}\text { Feedback is } \\
\text { provided for 3 } \\
\text { of 4 parts of } \\
\text { the assessment. }\end{array}$ & $\begin{array}{l}\text { Feedback is } \\
\text { provided 2 of 4 } \\
\text { parts of the } \\
\text { assessment. }\end{array}$ & $\begin{array}{l}\text { Feedback is } \\
\text { provided for 1 } \\
\text { of 4 parts of the } \\
\text { assessment. }\end{array}$ & $\begin{array}{l}\text { Feedback is } \\
\text { not provided. }\end{array}$ \\
\hline
\end{tabular}




\begin{tabular}{|l|l|l|l|l|l|}
\hline $\begin{array}{l}\text { Constructive } \\
\text { and } \\
\text { actionable }\end{array}$ & $\begin{array}{l}\text { Feedback is } \\
\text { constructive and } \\
\text { all aspects are } \\
\text { actionable. }\end{array}$ & $\begin{array}{l}\text { Feedback is } \\
\text { constructive } \\
\text { and many } \\
\text { aspects are } \\
\text { actionable. }\end{array}$ & $\begin{array}{l}\text { Feedback is } \\
\text { somewhat } \\
\text { constructive, } \\
\text { and some } \\
\text { aspects are } \\
\text { actionable. }\end{array}$ & $\begin{array}{l}\text { Feedback is } \\
\text { largely } \\
\text { descriptive and } \\
\text { not actionable. }\end{array}$ & $\begin{array}{l}\text { Feedback is } \\
\text { wholly } \\
\text { descriptive and } \\
\text { not actionable. }\end{array}$ \\
\hline Action plan & $\begin{array}{l}\text { There were } \\
\text { many } \\
\text { suggestions } \\
\text { given for further } \\
\text { improvements. }\end{array}$ & $\begin{array}{l}\text { Numerous } \\
\text { suggestions for } \\
\text { improvement } \\
\text { of performance } \\
\text { were provided. }\end{array}$ & $\begin{array}{l}\text { A number of } \\
\text { suggestions for } \\
\text { improvement } \\
\text { of performance } \\
\text { were provided. }\end{array}$ & $\begin{array}{l}\text { Minimal } \\
\text { suggestions for } \\
\text { improvement of } \\
\text { performance } \\
\text { were provided. }\end{array}$ & $\begin{array}{l}\text { Suggestions } \\
\text { for } \\
\text { improvement } \\
\text { of } \\
\text { performance } \\
\text { were not } \\
\text { provided. }\end{array}$ \\
\hline Language & $\begin{array}{l}\text { Language used } \\
\text { was consistently } \\
\text { professional. }\end{array}$ & $\begin{array}{l}\text { Language used } \\
\text { was } \\
\text { professional for } \\
\text { the most part } \\
\text { with occasional } \\
\text { lapses. }\end{array}$ & $\begin{array}{l}\text { Language used } \\
\text { was } \\
\text { professional } \\
\text { with some } \\
\text { lapses. }\end{array}$ & $\begin{array}{l}\text { Language used } \\
\text { was somewhat } \\
\text { professional but } \\
\text { requires } \\
\text { substantial } \\
\text { improvement. }\end{array}$ & $\begin{array}{l}\text { Language used } \\
\text { was not } \\
\text { professional. }\end{array}$ \\
\hline
\end{tabular}

Appendix 2: Feedback Literacy and Attitudes Survey

Using the following scale, please respond to each of the statements below:

5 - Strongly agree

4 - Agree

3 - Neither agree nor disagree

2 - Disagree

1 - Strongly disagree

\begin{tabular}{|c|c|c|c|c|c|}
\hline Question & & sp & nse & & \\
\hline $\begin{array}{l}\text { 1. I understand the purpose of feedback is to improve learning and } \\
\text { academic performance }\end{array}$ & 1 & 2 & 3 & 4 & 5 \\
\hline $\begin{array}{l}\text { 2. I understand the differences between effective and ineffective } \\
\text { feedback }\end{array}$ & 1 & 2 & 3 & 4 & 5 \\
\hline $\begin{array}{l}\text { 3. I consider feedback to be important for my learning and academic } \\
\text { performance }\end{array}$ & 1 & 2 & 3 & 4 & 5 \\
\hline $\begin{array}{l}\text { 4. I provide feedback to my peers to improve their academic } \\
\text { performance }\end{array}$ & 1 & 2 & 3 & 4 & 5 \\
\hline $\begin{array}{l}\text { 5. I feel my academic performance improves when I receive effective } \\
\text { feedback }\end{array}$ & 1 & 2 & 3 & 4 & 5 \\
\hline 6. I use feedback to reflect on my learning and academic performance & 1 & 2 & 3 & 4 & 5 \\
\hline $\begin{array}{l}\text { 7. I am open to receiving critical feedback on my academic } \\
\text { performance }\end{array}$ & 1 & 2 & 3 & 4 & 5 \\
\hline $\begin{array}{l}\text { 8. I am comfortable receiving critical feedback on my academic } \\
\text { performance }\end{array}$ & 1 & 2 & 3 & 4 & 5 \\
\hline 9. I actively seek feedback on my academic performance from peers & 1 & 2 & 3 & 4 & 5 \\
\hline $\begin{array}{l}\text { 10. I actively seek feedback on my academic performance from } \\
\text { teachers }\end{array}$ & 1 & 2 & 3 & 4 & 5 \\
\hline 11. I am confident providing feedback to myself and others & 1 & 2 & 3 & 4 & 5 \\
\hline 12. I have the skills and knowledge to provide effective feedback & 1 & 2 & 3 & 4 & 5 \\
\hline
\end{tabular}




\begin{tabular}{|l|l|l|l|l|l|}
\hline 13. I have the skills and knowledge to receive effective feedback & 1 & 2 & 3 & 4 & 5 \\
\hline $\begin{array}{l}\text { 14. I appreciate the role of effective feedback to improve my learning } \\
\text { and academic performance }\end{array}$ & 1 & 2 & 3 & 4 & 5 \\
\hline $\begin{array}{l}\text { 15. I need to actively engage in the feedback process to improve my } \\
\text { academic performance }\end{array}$ & 1 & 2 & 3 & 4 & 5 \\
\hline $\begin{array}{l}\text { 16. I use technology to access, store and revisit feedback provided to } \\
\text { me }\end{array}$ & 1 & 2 & 3 & 4 & 5 \\
\hline 17. I use technology to provide feedback to myself and others & 1 & 2 & 3 & 4 & 5 \\
\hline $\begin{array}{l}\text { 18. I use feedback from my teachers, peers and others to improve my } \\
\text { academic performance }\end{array}$ & 1 & 2 & 3 & 4 & 5 \\
\hline 19. I value feedback from my teachers over my peers & 1 & 2 & 3 & 4 & 5 \\
\hline $\begin{array}{l}\text { 20. I develop my own strategies to improve learning and academic } \\
\text { performance based on feedback }\end{array}$ & 1 & 2 & 3 & 4 & 5 \\
\hline $\begin{array}{l}\text { 21. I implement strategies to improve my learning and academic } \\
\text { performance based on feedback from peers and teachers }\end{array}$ & 1 & 2 & 3 & 4 & 5 \\
\hline
\end{tabular}

\section{Declarations}

The author has declared that there are no conflicts of interest.

This has been published under Creative Commons "CC BY 4.0" (https://creativecommons.org/licenses/by-sa/4.0/)

\section{Ethics Statement}

Ethical approval was obtained from the Victoria University Human Research Ethics Committee (Approval Number:

HRE 17-192).

\section{External Funding}

This article has not had any External Funding

MedEdPublish: rapid, post-publication, peer-reviewed articles on healthcare professions' education. For more information please visit www.mededpublish.org or contact mededpublish@dundee.ac.uk. 


\section{University Library}

\section{- M M I N E R VA A gateway to Melbourne's research publications}

Minerva Access is the Institutional Repository of The University of Melbourne

Author/s:

Tripodi, N;Vaughan, B;Wospil, R

Title:

Peer feedback as a strategy to foster feedback literacy in first-year allied health students

Date:

2021

Citation:

Tripodi, N., Vaughan, B. \& Wospil, R. (2021). Peer feedback as a strategy to foster feedback literacy in first-year allied health students. MedEdPublish, 10 (1), https://doi.org/10.15694/ mep.2021.000115.1.

Persistent Link:

http://hdl.handle.net/11343/274306

License:

CC BY-SA 